\title{
SMALL-GAP UNDULATOR EXPERIMENT ON THE NSLS X-RAY RING*
}

\author{
P.M. Stefan, S. Krinsky, G. Rakowsky and L. Solomon \\ NSLS-Brookhaven National Laboratory, P.O. Box 5000, Upton, NY 11973-5000
}

\begin{abstract}
We report results of an on-going experiment being carried out in the X13 straight section of the NSLS X-ray Ring which explores the limits of the operation of small-gap undulators. In particular, we discuss measurements of stored electron beam lifetime as a function of the vertical aperture presented by a 4-jaw scraper or a variable-aperture vacuum vessel. At an electron beam current of $300 \mathrm{~mA}$ the variable-aperture vacuum chamber was closed to an inner aperture of $3.8 \mathrm{~mm}$ with no effect on the electron beam lifetime. Measurements of the output radiation spectrum of a 16 mm period undulator at a magnet gap of $7.5 \mathrm{~mm}$ are also described.
\end{abstract}

\section{INTRODUCTION}

The limits of operation of small-gap, short-period undulators are being explored in the X13 low- $\beta$ straight section of the NSLS $\mathrm{X}$-ray Ring. Measurements of stored electron beam lifetime as a function of vertical aperture were made using both a 4-jaw scraper assembly and the variable-aperture vacuum vessel of the NSLS Prototype Small-Gap Undulator (PSGU). Some potential limitations on the electron beam aperture, and hence the undulator gap, are Coulomb scattering lifetime, transverse impedance of the vacuum chamber, vacuum pressure in the low-conductance region of the small aperture chamber, and possible ion trapping in this region.

\section{STUDIES OF BEAM LIFETIME VS. ELECTRON BEAM APERTURE}

\section{A. 4-jaw Scraper:}

While design and fabrication of the variable-aperture vacuum chamber were in progress, an existing 4-jaw scraper assembly was refurbished and installed in the X13 straight section of the X-ray Ring. The vertical blades of the scraper were located about 150 $\mathrm{mm}$ upstream of the X13 straight section centerline $\left(\beta_{\mathrm{y}}=0.4 \mathrm{~m}\right)$. The 4 scraper blades ( 2 horizontal, 2 vertical) were each $5 \mathrm{~mm}$ thick of uncooled copper and each was individually-controlled. Only a single blade was used at a time. Data were taken by moving one blade of the scraper in small steps and measuring the beam lifetime which resulted. Lifetimes were calculated by the change in amplitude of a stripline sum signal over time, which was monitored at $53 \mathrm{MHZ}$ using a spectrum analyzer.

Fig. 1 presents results taken using both the upper and lower scraper blades. The initial stored beam was $21 \mathrm{~mA}$ at $2.584 \mathrm{GeV}$, in 25 bunches and used the conventional vertical-beam-size optics
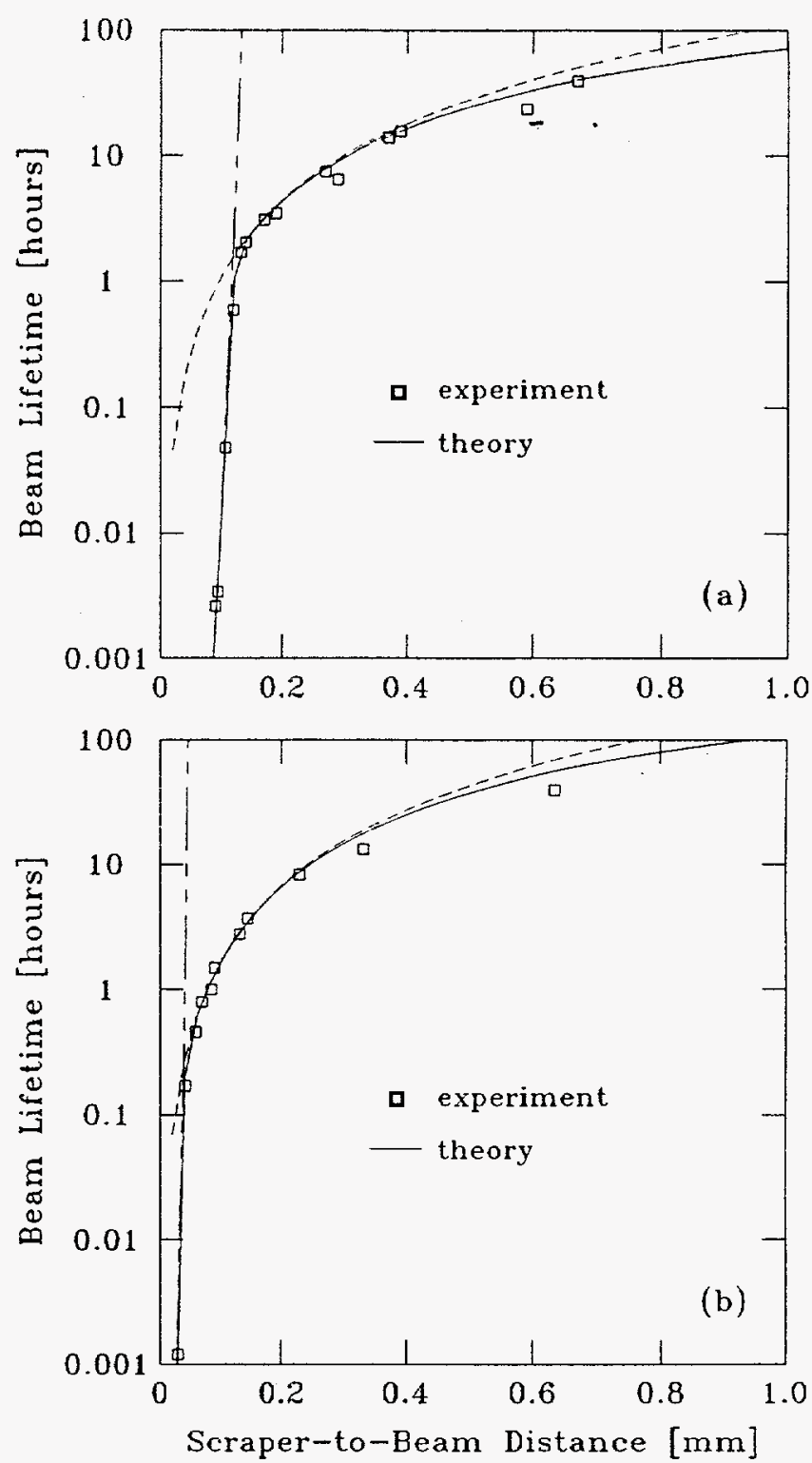

Figure 1: Vertical scraper results at low current: $21 \mathrm{~mA}$ at 2.584 Gev. Two components of the theoory curve are also illustrated, the quantum lifetime (section line) and the nuclear Coulomb scattering lifetime for the vertical (dashed line). (a) $\sigma_{y}=20 \mu \mathrm{m}$; (b) $\sigma_{y}=7 \mu \mathrm{m}$.

(a) and the small beam size optics (b) [1]. The theory curve [2] contains four contributions: the quantum lifetime, the nuclear Coulomb scattering lifetime for both horizontal and vertical apertures, and the nuclear bremsstrahlung lifetime. Of these, only the quantum and the vertical Coulomb components depend on the vertical beam aperture, and are illustrated in the figure using the section line and dashed line, respectively. One observes that Coulomb scattering dominates at longer lifetimes, but short 
lifetimes are dominated by the quantum lifetime. The theoretical curve was fit to the data using a number of adjustable parameters. The experimental points from the upper blade were offset along the abscissa by a constant [(a) $130 \mu \mathrm{m}$; (b) $185 \mu \mathrm{m}]$ due to the lack of absolute position calibration of the scraper blades, while the points caken using the lower blade were reflected about the origin and offset as a group to overlay the other points. The storage ring pressure was adjusted in the formulas for best fit where the vertical Coulomb scattering dominates [(a) $0.23 \mathrm{n}$ torr; (b) $0.15 \mathrm{n}$ torr], and the vertical beam size was similarly adjusted for best fit for lifetimes below 1 hour $\left[(\mathrm{a}) \sigma_{y}=20 \mu \mathrm{m}\right.$; (b) $\left.\sigma_{y}=7 \mu \mathrm{m}\right]$. Of these adjustable parameters, the resulting ring pressure seems somewhat too low, but the other parameters seem reasonable. These results, together with other data taken at low current and high current, suggest that the full ring lifetime is attained at a full aperture of about $2 \mathrm{~mm}$. This result is about half the minimum aperture expected from scaling the aperture at the $\beta$-max by the square-root of the beta function, and suggests the possibility that the PSGU might operate down to a $2.5 \mathrm{~mm}$ aperture without lifetime degradation.

\section{B. PSGU Variable-Aperture Vacuum Chamber}

The NSLS Prototype Small-Gap Undulator is comprised of three major components: a variable-aperture vacuum chamber with drive system, a pure-permanent-magnet small-period undulator with an independent drive system, and an elevator base stage upon which all of the above components are supported. The design concept of the variable-aperture chamber has been described elsewhere [3], and is summarized in Fig. 2.

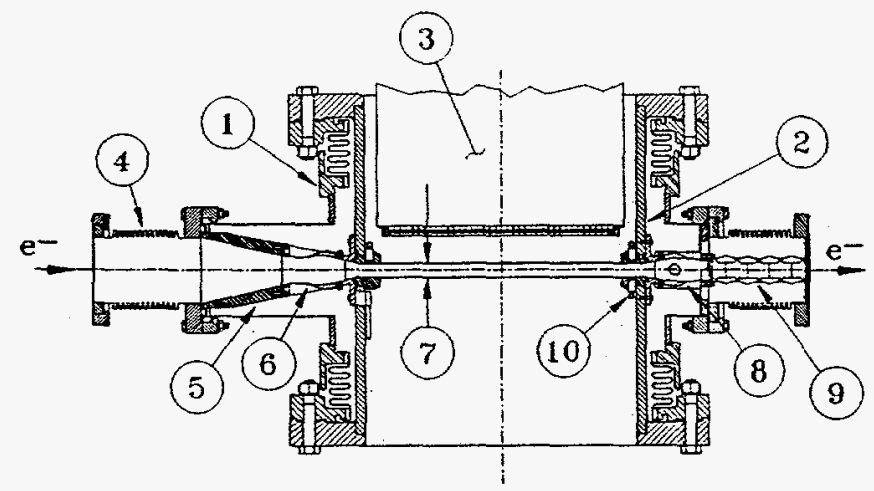

Figure 2: Elevation cross section of the variable-aperture vacuum chamber, with the electron beam in the plane of the page. See text for detailed description.

The figure presents an elevation cross section of the vacuum chamber, with the electron beam contained in the plane of the page. Deep wells, from the top and bottom flanges, extend towards the stored beam and can be moved closer together or farther apart by means of top and bottom bellows. The central section of the chamber(1), between the bellows, is fastened through legs to the elevator base stage below. Actuators attached between the two flanges control the electron beam aperture. The portions of the wells near the stored beam(7) are thinned to $1 \mathrm{~mm}$, and the magnet arrays of the undulator(3) are inserted into the wells, up near the thinned region. The chamber(1) is cylindrical, about $460 \mathrm{~mm}$ in diameter, with its axis oriented vertically. For these experiments, the electron beam aperture (7) could vary between $14 \mathrm{~mm}$ and 3.8 $\mathrm{mm}$, and the minimum-aperture region is $104 \mathrm{~mm}$ wide and 390 mmlong. PSGU is located in the X13 straight section of the NSLS $X$-ray Ring, with the axis of the vacuum chamber(1) $15 \mathrm{~mm}$ downstream of the straight centerline.

Further details of the vacuum vessel are also shown in Fig. 2. The beam enters the minimum-aperture region through an $89 \mathrm{~mm}$ diameter hydroformed-type bellows(4), a solid round-to-rectangular transition(5), and a set of flexible sheet-metal transitions(6). It exits through a similar sheet-metal transition(8), followed by a rectangular sheet-metal bellows liner(9). The vertical location of the electron beam within the minimum aperture is detected using pairs of pick-up electrodes(10) located at the upstream and downstream ends of the movable wells.

The implications of the 4-jaw scraper results were verified with the PSGU variable-gap vacuum chamber. When centered on the electron beam and closed to the minimum aperture of $3.8 \mathrm{~mm}$, no change in the storage ring lifetime was observed. This was true not only for low beam currents, but also for $300 \mathrm{~mA}$ at $2.584 \mathrm{GeV}$, which is above the limits for present normal operations. No instability from vacuum chamber impedance was observed, confirming expectations from theory [4] and impedance measurements [5].

To reduce the electron beam aperture below $3.8 \mathrm{~mm}$, the small-aperture region was offset from its initial position (centered on the electron beam) by use of the elevator base stage. The results appear in Fig. 3. The stored beam conditions were essentially the

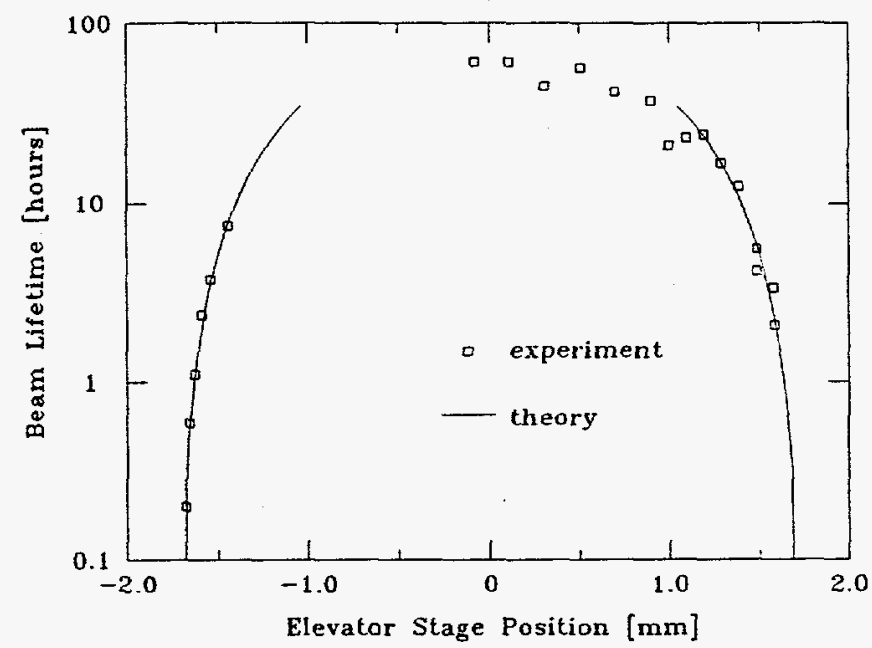

Figure 3: Results of vertical translation of the $3.8 \mathrm{~mm}$ minimumaperture region. These results suggest that a minimum full aperture of 2 to $3 \mathrm{~mm}$ might be used without lifetime degradation.

same as for the scraper results presented in Fig. 1b, and utilized the small-vertical-beam-size optics [1] . The theory curve was 


\section{DISCLAIMER}

This report was prepared as an account of work sponsored by an agency of the United States Government. Neither the United States Government nor any agency thereof, nor any of their employees, makes any warranty, express or implied, or assumes any legal liability or responsibility for the accuracy, completeness, or usefulness of any information, apparatus, product, or process disclosed, or represents that its use would not infringe privately owned rights. Reference herein to any specific commercial product, process, or service by trade name, trademark, manufacturer, or otherwise does not necessarily constitute or imply its endorsement, recommendation, or favoring by the United States Government or any agency thereof. The views and opinions of authors expressed herein do not necessarily state or reflect those of the United States Government or any agency thereof. 


\section{DISCLAIMER}

Portions of this document may be illegible in electronic image products. Images are produced from the best available original document. 
generated as in the previous case, but offset to match the data, and reflected about the $0 \mathrm{~mm}$ position. The adjustable parameters required were 0.3 ntorr for the pressure and $\sigma_{y}=8.5 \mu \mathrm{m}$. The quantum lifetime dominates the theory curve for lifetimes below. 0.1 hours; otherwise, the Coulomb scattering lifetime is dominant. The lifetime with the aperture centered on the electron beam was about 61 hours, as can be seen from Fig. 3. It is seen that the aperture can be offset by more than $0.5 \mathrm{~mm}$ before there is any lifetime degradation, suggesting that a full aperture of between 2.8 $\mathrm{mm}$ and about $1.8 \mathrm{~mm}$ may be imposed with long lifetimes. This strongly motivated a re-work of the vacuum chamber to achieve reduced apertures while centered on the electron beam.

\section{MEASUREMENT OF UNDULATOR RADIATION}

Following installation of the PSGU magnet and drive system, the X13 beamline was modified and a simple single-crystal $\mathrm{X}$-ray spectrometer was installed to measure the radiation spectrum. The result [6] appears in Fig. 4.

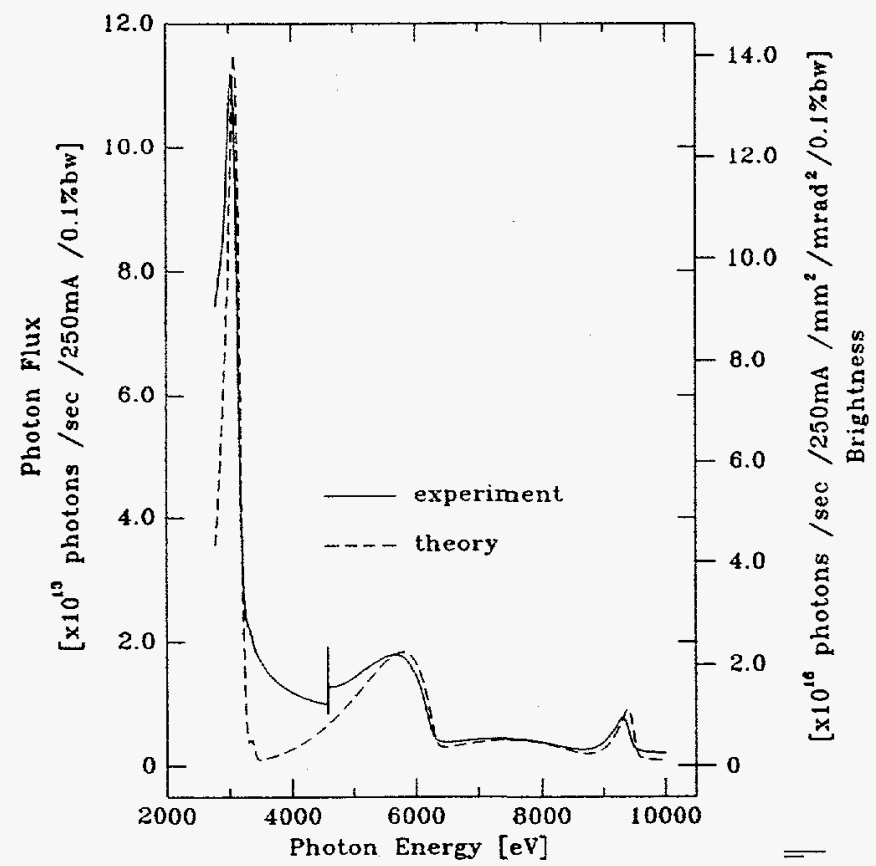

Figure 4: Spectrum measured for the $16 \mathrm{~mm}$ period undulator at a magnet gap of $7.5 \mathrm{~mm}, \mathrm{~K}=0.716$, at $2.584 \mathrm{GeV}, 26 \mathrm{~mA}$, with a minimum aperture of $3.8 \mathrm{~mm}$. The theory curve was obtained using the URGENT [7] code.

The beam current was kept low to prevent overheating of the beamline Be window. The theory curve was obtained from the URGENT code [7], by specifying the basic undulator and storage ring parameters, the undulator K-parameter, and the location and size of the spectrometer slit. The processing of the experimental data involved almost no adjustable parameters. The absorption of the Be window and of the spectrometer gas (either $\mathrm{He}$ or $\mathrm{N}_{2}$ ) was removed, and the absolute efficiency of the ion chamber was calculated using absorption coefficients and the chamber dimensions. Finally, the bandwidth of the Si(III) analyzer was included. There was a significant scattered background from the analyzer crystal in the detected signal, especially in the case with He gas. In the He data, a constant background was subtracted to bring the lowest part of the curve back to zero. In Fig. 4, the short vertical line in the experiment curve at about $4.6 \mathrm{KeV}$ is the splice point between the data taken with $\mathrm{He}$ gas (to lower energies) and that taken with $\mathrm{N}_{2}$ gas (higher energies). Good agreement is seen between the theory and the experimental results.

\section{CONCLUDING REMARKS}

We have successfully operated a small-gap undulator with a full vertical electron beam aperture of only $3.8 \mathrm{~mm}$, with no degradation of beam lifetime. Measurements carried out using the elevator stage strongly suggest that successful operation will be possible for a vertical beam aperture less than $3 \mathrm{~mm}$. In order to verify this, we have re-worked the PSGU vacuum chamber to permit a minimum aperture of $1 \mathrm{~mm}$. Following the re-installation of the system in May 1995, we believe we will be able to achieve the design goal of a $6 \mathrm{~mm}$ magnet gap.

\section{ACKNOWLEDGEMENT}

We have benefited from discussions with E. Hoyer, J. Hastings, J. Galayda, H.C. Hseuh, G. Decker and E. Blum, and the contributions of D. Lynch, S. Hanna, J. Aloia, C. Stelmach, M. Radulescu, R. Freudenberg, D. Klein, C. Nielson, J. Dabrowski, L.E. Berman and D.P. Siddons. Work performed under the auspices of U.S. Department of Energy, under Contract DE-AC02$76 \mathrm{CH} 00016$.

\section{REFERENCES}

[1]J. Safranek and S. Krinsky, Proc. 1993 IEEE Part. Accel. Conf., Washington, DC, (1993), p. 1491.

[2]Our analysis benefits from earlier work of G. Decker, unpublished, who used the scraper when it was located at a position where $\beta_{y}=7 \mathrm{~m}$.

[3]P.M. Stefan, L. Solomon, S. Krinsky and G. Rakowsky, Proc. 1991 IEEE Part. Accel. Conf., San Francisco, CA, (1991) p. 1096.

[4]K. Bane and S. Krinsky, Proc. 1993 IEEE Part. Accel. Conf., Washington, DC., (1993), p. 3375.

[5]S. Hanna and P. Stefan, unpublished.

[6]P.M.Stefan, S. Krinsky, G. Rakowsky and L. Solomon, in "A Festschrift in Honor of Klaus Halbach", LBL PUB-754, p. 161.

[7]R.P. Walker and B. Diviacco, Rev. Sci. Instrum., 63(1), 392, (1992). 